however, the progress which has been made in the use of the important term 'subsong' by referring it to all forms of quiet song. Thorpe's restrictive definition based on acoustic characteristics which is discarded is, in fact, a model of clarity which ought to be imitated in the definition of other vague terms, such as that of song itsolf.

The strength of this book, its wide-ranging comprehensiveness, is also the source of a weakness, which is a tendency to overlook differences in the quality of evidence. The importance of results obtained with modern instruments and critical experiments is not sufficiently emphasized. It is disappointing to find the experimental results obtained by Thorpe on song in the chaffinch placed on the same footing as the observations of bird fanciers. The latter have known long ago that experience plays a part in the development of song, but such information is usually anecdotal in character and mixed with unreliable notions which must be tested.

In the later chapters there are many interesting pages on such topics as mimicry, dialects, duetting, and the variety of functions performed by song. There are numerous useful suggestions and critical comments on the interpretation of the facts, and indications of directions for fruitful future research. Anyone who has seriously asked if singing birds possess an æesthetic sense will enjoy the final chapter on bird song as art and play. Perhaps the disagroement reflected in the discussion of C. Hartshorne's ideas on the effect of the monotony threshold will stimulate research on this interesting hypothesis. The book will join earlier works by this author as an important contribution to the investigation of bird song, serving as a comprehensive guide to the work carried out and a valuable aid to the formation of general principles in this subject.

J. A. Muluigan

\section{NATURAL PLANT GROWTH REGULATORS}

\section{Régulateurs Naturels de la Croissance Végétale}

(Colloques Internationaux du Centre National de la Recherche Scientifique, No. 123, Gif-sur-Yvette, 15-20 Juillet, 1963.) Pp. 748. (Paris: Edition du Centre National de la Recherche Scientifique, 1964.) n.p.

REGULATEURS Naturels de la Croissance Végétale reports the proceedings of the fifth in the series of international conferences on plant growth regulators, which was held at Gif-sur-Yvette in July 1963, under the auspices of the Centre National de la Recherche Scientifique. Most of the text is, however, in English. These colloquia provide an opportunity of surveying the rapidly developing subject of plant growth substances. This subject is now very wide, covering a large range of synthetic substances including woedkillers, so the restriction in this colloquium to natural growth regulators not only kept the subject within bounds, but also re-emphasized the importance of understanding the occurrence and action of naturally occurring substances which is essential to an understanding of the action of synthetic substances.

The organizers are to be congratulated on their choice of topies, so that the roles of plant growth substances from cell division to senescence were discussed in a comprehensive manner.

Twelve papers are concerned with the regulation of cell division. The introductory pæpers describe the complex molecular mechanisms of cellular regulation which are necessary for cell division and the processes which anticipate mitosis. Interest in cell division factors in plants is at present centred on the environment of the embryo, and several papers describe the isolation and characterization of substances from doveloping seeds and fruits. Coconut milk contains cell division factors, and it is not surprising, therefore, that much of the effect in this field has been directed to the isolation and characterization of substances which induce cell division in plant tissue cultures. The results are, at the moment, somewhat contradictory, and several substances, belonging to widely different chemical groups, have been identified which accelerate cell division; however, the isolation of three different phytokinins in coconut milk is probably significant. Progress is hampered by lack of a comprehensive range of bioassay methods for cell division factors. The interesting fact is recorded that the bleeding sap of Vitis also contains phytokinin-like substances which are probably synthesized in the root. Phytokinins may have effects other than on cell division, and their regulating effects on attraction and retention of nutrients have important implications in the transport of such substances to 'sinks', especially immature seeds and fruits. The largest section (sixteen papers) is concerned with the regulation of cell enlargement. Much of the effort is at present concerned with the form in which indoles occur in the plant and their transformation during growth. There is evidence that auxin interacts with macromolecular constituents of plants, for example, RNA. Six of this group of papers discuss the role of gibberellins, including their biosynthesis.

We know loss of the occurrenco and nature of natural growth inhibitors than of growth-promoting substances. One difficulty is to know whether a substance which acts as a growth inhibitor in vitro has the same role in vivo. This problem is well illustrated in five papers concerned with synergists and natural inhibitors. Some naturally occurring phenolic substances inhibit the growth of plant tissues at high concentration, but at lower concentrations growth may be stimulated. This suggested that such substances exert their effect through the indoleacetic acid oxidase system. In a discussion on dormancy it is pointed out that 'rest' stages of plant organs may be due either to the presence of growth-inhibiting substances or absence of growth-promoting substances. The first hypothesis is supported by a correlation between seasonal changes in bud dormancy and corresponding variations in the level of endogenous inhibitors.

Success in isolating the true growth-promoting substances from plants depends on the methods used. This problem is discussed in five papers using techniques of gas, paper and thin-layer chromatography and spectrophotofluorimetry.

Our knowledge of how growth substances regulate vegetative growth is still meagre. Widely ranging aspects of this topic are presented in seven papers and include the relative contributions of cell division and cell expansion to growth, the relation between contents of auxin and gibberellins to leaf growth, the substances governing root initiation and root growth. The polar transport of auxin and its modifications by unilateral influences have important implications in explaining geotropism and phototropism. The domonstration of the presence of minute crystalline bodies in apical cells of the Avena coleoptile which may act as photoreceptors in phototropism is a significant advance. The chapters on the regulation of flowering are mainly concernod with identification of substances which cause bolting or induce flower differentiation. No one can yet claim to have characterized such a substance, but it is encouraging that active crystalline extracts have been prepared. Finally, the four papers on senescence indicate the progress made towards an understanding of abscission processes and the role of phytokinins in regulation of leaf senescence.

This volume summarizes our knowledge of plant growth substances up to 1963 but, with rapid developments in this field, the information will soon be out of date. It is perhaps unfortunate, therefore, that it was considered necessary to have such a luxurious production.

E. C. HUMPHRIES 